\title{
Die onkunde van die Jode en hulle verwerping van die evangelie
}

\author{
DM van Zyl \\ Pretoria
}

\begin{abstract}
The ignorance of the Jews and their rejection of salvation

The aim of this paper is to answer the question on just how much the Jews could rely on their ignorance in rejecting Jesus Christ and his message of salvation. This could not be answered without viewing Luke's attitude towards the Jews. The paper argues further that the predestination of God played a significant role. In the end the whole question is concerned with the conversion of the Jews after their 'previous state of ignorance'.
\end{abstract}

\section{PROBLEEMSTELLING}

Die skuld vir die verwerping van Jesus en daarmee saam die evangelieboodskap, word deurgaans in die Lukasevangelie en in die boek Handelinge van die Apostels voor die deur van die Jode gegooi. Wanneer Lukas dan in Handelinge 3: 17 skryf: 'Nou weet ek, broers, dat julle net soos julle leiers in onkunde gehandel het', ontstaan die vraag wat hy daarmee bedoel het. Het die onvermoë van die Jode om Jesus as die Messias te erken gelei tot hulle verontskuldiging?

\section{LUKAS SE HOUDING TEENOOR DIE JODE}

In beide die geskrifte van Lukas vind ons nie bloot ' $n$ onderskeid tussen Jode en heidene nie, maar ook binne die Joodse gemeenskap skets Lukas sekere 'groepe' as positief en ander as negatief met betrekking tot die Evangelie (Groenewald 1973: 93; Van der Watt 1982: 56). Daar is ook 'n besliste onderskeid te bespeur in Lukas se houding teenoor die volk (oorwegend positief) en teenoor die leiers van die Jode (oorwegend negatief) (Walasky 1983: 28-9; Luk 20: 1, 9, 19; 21: 38; 22: 2; 23: 5; 35, 48). 


\subsection{Die Joodse leiers}

Tot en met Lukas 19: 28-44 word die skuld vir Jesus se kruisiging en die hele beplanning van die komplot teen Jesus hoofsaaklik op die Fariseërs gelê. Met die intog in Jerusalem en daarna, word daar meer eksplisiet teen die skrifgeleerdes en owerpriesters berig (Conzelmann 1969: 78; Johnson 1977: 116). Lukas laat duidelik blyk dat dit die Joodse leiers is wat vir Jesus se dood verantwoordelik gehou kan word (Karris 1974: 28). Tog kan daar nie werklik van die Joodse leiers as ' $n$ homogene groep gepraat word nie (Luk: 5: 17; 11: 37-54; Hand 23), en is daar naas die Fariseërs en skrifgeleerdes ook sprake van owerpriesters, die Sadduseërs, die hoëpriesters, die Sanhedrin, priesters en so meer.

Cassidy en Scharper (1983: 132) gee in hierdie verband die volgende samevatting vanuit ' $n$ vergelyking tussen die vier Evangelies:

It is primarily the chief priests, with the scribes and elders, who accomplish Jesus' crucifixion in Mark's Gospel. It is primarily the chief priests, with the help of the elders, who do so in Matthew's account. It is the chief priests working through the soldiers and officers, who acchieve Jesus' death in John's Gospel. By contrast, it is various individuals and groups, among whom the chief priests consistently appear, who put Jesus to death.

Die leierselement in die geskrifte van Lukas dra die primêre skuld vir die kruisiging van Jesus, terwyl die sekondêre skuld aan die volk toegesê word. Hierdie tendens vind ons ook in die boek Handelinge van die Apostels (Cassidy \& Scharper 1983: 133). Veral in terme van die vervolging van die Christene deur die Joodse leiers in die boek Handelinge vind ons die negatiewe beriggewing van Lukas. Waar die veldtog in die Lukasevangelie teen Jesus gerig word, verskuif die klem na Paulus en ander Christene in Handelinge en bestaan daar ' $n$ sterk ywer om die Christendom daarmee saam te vernietig (De Villiers 1983: 169; Haencen 1971: 666). Hoewel die Joodse leiers dan hoofsaaklik in 'n sterk negatiewe sin beskryf word in die geskrifte van Lukas, kan ons ons met Tannehill (1985: 81) vereenselwig dat daar nie sprake is van 'n negatiewe stereotipering van anti-Semitisme nie en behoort mens eerder te praat van die tragiek agter die beskrywing van die Jode. In punt 3 kom ons weer hierna terug.

\subsection{Die Joodse volk}

Ons het reeds daarop gewys dat die breë bevolking (die volk, die Jode, ensovoorts) nie in dieselfde negatiewe sin deur Lukas beskryf word nie. 
Volgens Lukas 24: 20 is slegs die priesterhoofde en skrifgeleerdes betrokke by Jesus se dood. In Lukas 23: 35, 48 en Handelinge 1-5 is die volk aan die kant van die dissipels wat heeltemal in teenstelling is met die leiers (Luk 20: 1, 9, 19; 21: 38; 22: 2).

Tog wys Schweizer (1984: 302, 351) en Edwards (1981: 91) daarop dat die kruisiging deur almal aangemoedig is (Luk 23: 13-23; Hand 2: 23, $36 ; 4: 10 ; 13: 27-8)$. Hoewel Lukas dus deurgaans die blaam net op die leiers geplaas het, hou Lukas uiteindelik in 23: 13-23 ook die volk verantwoordelik vir die kruisiging (Schweizer 1984: 353; Edwards 1981: 91).

Die positiewe lig waarin Israel aan die begin van die Evangelie gestel word blyk gou te vervaag en veral in die boek Handelinge, na die Stefanus-gebeure (Hand 7), verwerp die Jode die Woord telkens (Hand 13: 44-7; 18: 6; 28: 24-8). Tog propageer Lukas nooit die verwerping van Israel nie en is daar ondanks Israel se skuld aan die verwerping van Jesus en die Evangelie altyd weer die aanbod van vergifnis (Noordegraaf 1983: 196).

\section{DIE ONKUNDE VAN DIE JODE (HAND 3: 17)}

Handelinge 3: 17 verwys na die onkunde van die Jode in hul verwerping en kruisiging van Christus: 'Nou weet ek, broers, dat julle net soos julle leiers in onkunde gehandel het.' Die vraag ontstaan daarom of die sogenaamde onkunde van die Jode hulle verontskuldig het.

Tekskrities bemerk ons egter verskeie veranderinge in die Westerse teks (D, E, it ${ }^{h, p}$, cop ${ }^{G 67}$ ): Ten eerste word adelfoi in 'n meer algemene uitdrukking verander naamlik ándres adelfoí; tweedens word die meervoudsvorm van die werkwoord epistámetha (vir oîda) in harmonie met die voorafgaande hēmeîs (vers 15) gebruik en ten derde word ponèrón na epráxate ingevoeg om die idee tuis te bring dat hoewel die Jode se aandeel in Jesus se dood weens onkunde geskied het, dit nogtans 'n misdaad was. Deur verder mèn in vers 17 te voeg is daar ook 'n skerpe kontras uitgewys tussen die misdaad van die Jode en die doel van God wat in vers 18 uitgedruk word (Metzger 1971: 313). Die tekskritiese getuienis is egter onvoldoende om 'n verandering van die soort te aanvaar aldus Williams (1964: 79), waarby Alexander (1963: 112) ook meld dat weens die fase hōsper kaì (net soos) daar nie gedui word op kontras nie, maar op vergelyking.

Die 'onkunde - faktor' kom ook elders in die boek Handelinge van 
die Apostels voor naamlik in 13: 27 en 17: 30 (Moulton and Geden 1978: 14). Daarmee saam is dit die mening van verskeie kommentatore dat die onkunde (ágnoia) waarvan 3: 17 spreek, nie los gesien moet word nie van Lukas 23: 34.

'Toe sê Jesus: Vader, vergeef hulle, want hulle weet nie wat hulle doen nie!' asook van Stefanus se woorde in Handelinge 7: 60 'Toe het hy op sy knieë neergesak en hard uitgeroep: "Here, moet hulle tog nie hierdie sonde toereken nie!" (Alexander 1963: 112; Booysens 1978: 27; Bruce 1981: 90; De Villiers 1977: 76; Haenchen 1971: 207).

Bauernfeind (1980: 64) maak verder die uitlating:

Die Botschaft von der Verwerfung des

Messias durch sein eigenes Volk

konnte christliches Kerygma nur in

Verbindung mit zwei weiteren

Sätzen sein: 1. Der Messias

war nicht als solcher erkannt;

2. Sein Lebensausgang war von

Gott gewollt und in der Schrift geweissagt.

Struktureel beskou moet ons dit myns insiens nog breër as Bauernfeind sien. Moontlik kan ons die 'onkunde - faktor' in die volgende struktuur beskou:

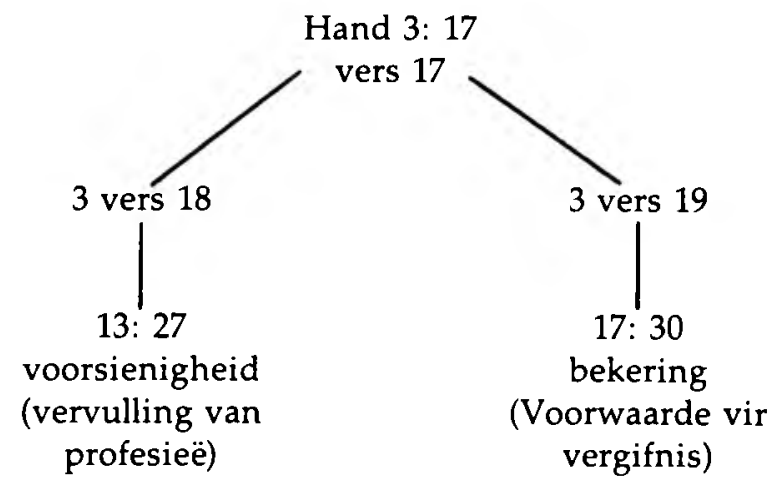

Die aanvang van Handelinge 3: 17 kaí nûn (en nou) is 'n algemene uitdrukking wat dui op die verplasing van aandag na 'n ander onderwerp as die voorafgaande of die gevolgtrekking van wat vooraf gestel is (Alexander 1971: 111). 
Betreffende die inhoud van vers 17 kan daar twee weë gevolg word: Eerstens word die mening gehuldig dat vers 17 'n genadige vryskelding is van die Jode of te wel 'n opheffing van hulle skuld in hul aandeel aan die dood van Jesus Christus. Dit sou nie alleen dui op 'n logiese verklaring van die grammatika nie, maar sou ook inpas by die woorde van Christus in Lukas 23: 34 asook Stefanus se uitroep in Handelinge 7: 60. Andersyds is daar die beskouing dat daar geen verontskuldiging bestaan nie en dat die feit dat hulle onkundig en onwetend te werk gegaan het, die Jode se skuld net beklemtoon. Vers 18 wat verwys na die vervulling van die profesie blyk hierdie argument te ondersteun maar die beperkte beskouing van onkunde (ágnoia) wil hierdie beskouing verswak.

Vers 18 (ho dè) en vers 19 (ô̂n) kan beide terugverbind word na vers 17 en laasgenoemde moet daarom daardeur verklaar word. In my skema het ek reeds verwys na die voorsienigheid van God (vers 18) asook die voorwaarde/bekeringsopdrag (vers 19) wat die onkunde in vers 17 toelig.

Betreffende die profesieë waarna Handelinge 3: 18 asook 13: 27 verwys: Die feit dat Jesus se dood voorspel is, was egter nooit op sigself ' $n$ verskoning of verontskuldiging van die Jode nie. Tereg skryf Booyens (1978: 28) dat ons ons nie kan vrypleit deur ons te beroep op die verborge raad van God nie - ons moet luister na sy geopenbaarde wil.

Vanuit Handelinge 3: 19 blyk dit dat die Jode nou opgeroep word tot bekering. Booyens (1978:27) vermeld dat daar onvergeeflike sondes is (Num 15: 30; Matt 12: 31-2; 1 Joh 5: 16) en dat die enigste maatstaf vir wanneer ' $n$ sonde onvergeeflik is, volharding in ongeloof is (Luk 23: 39-43). Die Jode se onwetenheid is vergeeflik, maar bly tog sonde en maak hulle skuldig. Daarom moet hulle hulle bekeer! Omdat daar vergifnis van sonde is, volg die oproep tot bekering (De Villiers 1977: 76). Sien ook Handelinge 17: 30.

Petrus sê verder dat dit ook die geval met dié Joodse leiers was, dat hulle dit uit onwetenheid gedoen het. Uit die Lukasevangelie en die boek Handelinge van die apostels kry mens egter die indruk dat die Joodse leiers geweet het wat hulle doen en dat hulle nie in Jesus die Messias wou sien nie. Dit sou moontlik beter wees om die opmerking van Petrus in vers 17 hier in verband met die leiers eerder anders te verklaar. Ons sou dit dan so kon interpreteer dat die Joodse leiers die volk mislei het deur hulle vir hulle eie doel teen Jesus te gebruik.

Só gesien, kom Lukas 24: 20 tot sy reg, waar die Emmaüsgangers die 
skuld vir die kruisiging aan die leiers gegee het (De Villiers 1977: 76; Conzelmann 1969: 78; Johnson 1977: 116; Luk 20: 1, 9, 19; 21: 38; 22: 2).

Daar moet egter steeds in gedagte gehou word dat woorde van beide Jesus (Luk 23: 34) en Stefanus (Hand 7: 60) vir al die betrokkenes (dit wil sê Joodse leiers en die volk) bedoel was (Lenski 1946: 1134).

Tekskrities beskou, bestaan daar egter vele verskille met betrekking tot die insluiting van Jesus se kruiswoorde in Lukas 23: 34. Dit is opvallend dat betroubare manuskripte, soos kodekse Sinaïticus en Vaticanus asook $\mathrm{p}^{75}$, hierdie frase uitlaat. Daarby sluit sekere vertalings soos die RV, RSV en NEB die woorde ook uit terwyl UBS dit in hakies plaas (Marshall 1978: 867). Creed (1942: 286) laat die woorde ook uit, maar stel dat die woorde geloofwaardig kan wees ten opsigte van die soldate wat Jesus aan die kruis vasgespyker het. Daarenteen is daar persone wat hierdie lesing aanvaar (Marshall 1978: 867; Ellis 1974: 267).

Daar is baie argumente daarvoor én daarteen wat Marshall (1978: 867) uitvoerig bespreek. Ons aanvaar die woorde vir ons doeleindes onder andere omdat dit inpas in Lukas se denke. Daarby kan ons die afleiding maak dat Handelinge 7: 60 op Lukas 23: 34 gebou is (Marshall 1978: 868). Die verbintenis wat Jesus en Stefanus se woorde met mekaar gehad het, blyk duidelik te wees (Marshall 1980: 150).

In ons skema koppel ons Handelinge 3: 15 aan 13: 27 waarin daar in beide teksgedeeltes daarna verwys word dat dit reeds lank te vore voorspel is dat Jesus gekruisig sou word. Marshall (1980: 225) berig dat hulle Jesus verwerp het omdat hulle Jesus nie erken het as die Messias nie en ook omdat hulle die profetiese getuienis nie erken het nie. Die aandeel wat die Romeine gehad het in Jesus se kruisiging word hier dus so stilweg oorgegee in die hande van die Jode en benadruk die Jode se aandeel in die vervulling van die profesieë ten opsigte van Jesus se dood, asook hoe hulle sy liggaam geneem het en dit gaan begrawe het (Luk 23: 53). Haenchen (1971: 410) maak die belangrike opmerking dat 3: $17 \mathrm{vv}$ en 13: $27 \mathrm{vv}$ nie dui op die eenheid van die prediking van die historiese Petrus en die historiese Paulus nie, maar op die samestelling van beide gedeeltes deur Lukas self, wie se teologie hier bekend gemaak word.

Ons kan ook hier vermeld dat Geldenhuys (1950: 608) in verband met Lukas 23: 34 'Vader, vergeef hulle, wat hulle weet nie wat hulle doen nie!'; stel dat Lukas besondere klem lê op die vergifnis van God vir die sondaar. Nogtans is dit duidelik dat die feit dat die Jode onkundig was én dat dit in die raadsplan van God ingesluit was dat Jesus deur die 
Jode verwerp en gekruisig sou word nie beteken dat die Jode per se verontskuldig is nie.

Daar moes nog ' $n$ faktor bykom en dit is die bekeringsopdrag wat ons vind in Handelinge 3: 19 en 17: 30.

\section{DIE VERGIFNIS/VERONTSKULDIGING VAN DIE JODE}

Daar is reeds gewys op die feit dat die Jode nie vergewe is bloot vanweë onkunde en die voorsienigheid van God nie. Hier kan nie sprake wees van ' $n$ blinde determinisme waaraan die Jode geen skuld kon dra nie. Vergifnis vir die Jode is egter moontlik indien hulle, hulle sou bekeer, met ander woorde terugdraai na God toe. Twee gevolge sal dan hieruit spruit: Tye van verkwikking sal van die Here af kom en Jesus sal terugkeer vanuit die hemel.

Handelinge 17: 30 lees: 'God het die tye van onkunde oorgesien, maar nou roep $\mathrm{Hy}$ al die mense oral op om hulle te bekeer...' Hierdie vers vertel dan ook in kort hoe ons ons probleem kan beantwoord. Haenchen (1971: 525) wys daarop dat Lukas hiermee aandui dat hy die onderwerp van onkunde nie vergeet het nie. Sou die Jood hom bekeer (dit sluit in die Joodse leier en lede van die volk van die tyd rondom die kruisiging deurlopend tot op hede) is daar vergifnis. Wanneer daar nie sprake van bekering is nie, sal nóg die voorsienigheid van God nóg sy onkunde hom kan red.

Ten slotte moet daar net gewys word daarop dat ons 'n besliste onderskeid moet tref tussen die onkunde-faktor by die Jode in die geskrifte van Lukas en die sake waarvan Paulus melding maak in Romeine 1: 18 en volgende vase wat 'n teologiese diskusse bevat ten opsigte van die wyse waarop God die mensdom as't ware oorgee aan sonde en die gevolge daarvan asook in Romeine 3: 25-6 waar die genade van God beklemtoon word en menslike onkunde nie verwerp word in sy prediking aan die heidene nie (Marshall 1980: 290). Ons het reeds in hierdie verband gewys op Lukas se eiesoortige teologie in ons bespreking van die onderwerp (Haenchen 1971: 410).

\section{NABETRAGTING}

Die realiteit daarvan dat die Jode (veral hulle leiers) die dood van Jesus bewerkstellig en ten uitvoer laat bring het, staan vas in Lukas. Daarmee saam was hulle nie in staat om Jesus te erken as die Messias van die 
Skrifte nie, maar dit op sigself was nie genoegsaam vir Lukas om hulle vry te spreek van hulle sondige dade nie. Vóór bekering bly die Jood skuldig, goddelike voorsienigheid ten spyte. Na die bekering lê daar ook dan soveel heerlike beloftes, ook vir die Jood. Die verontskuldiging van die Jode kan dus nie ongekwalifiseerd en simplisties instemmend of negatief beantwoord nie, maar kan alleen beantwoord word in verband met die oproep tot bekering.

\section{Literatuurverwysings}

ALEXANDER, JA 1963. The Acts of the Apostles. London: Morrison and Gibb.

BAUERNFEIND, O 1980. Kommentar und Studien zur Apostelgeschichte. Tübingen: Mohr. BOOYENS, MJ 1978. Julle sal my getuies wees. Pretoria: NG Kerkboekhandel.

BRUCE, FF 1981. The Acts of the Apostles. London: Tyndale.

CASSIDY, RJ \& SCHARPER, PJ 1983. Political issues in Luke-Acts. New York: Orbis.

CONZELMANN, H 1961. The theology of St. Luke. London: Faber and Faber.

CREED, JM 1942. The Gospel according to St. Luke. London: Macmillan \& Co.

DE VILLIERS, JL 1977. Die Handelinge van die Apostles, 1 en 2. Kaapstad: NG Kerkboekhandel.

EDWARDS, OC 1981. Luke's story of Jesus. Philadelphia: Fortress.

ELLIS, EE 1974. The Gospel of Luke. London: Oliphants.

GELDENHUYS, N 1950. Commentary on the Gospel of Luke. London: Marshall, Morgan and Scott.

GROENEWALD, EP 1973. Die Evangelie van Lukas. Pretoria: NG Kerkboekhandel.

HAENCEN, E 1971. The Acts of the Apostles. Oxford: Blackwell.

JOHNSON, LT 1977. The literary function of possessions in Luke-Acts. Missoula: Scholars.

LENSKI, RCH 1946. The interpretation of St. Luke's Gospel. Minneapolis: Augsburg Publishing House.

MARSHALL, IH 1978. The Gospel of Luke. Cape Town: Oxford University.

MARSHALL, IH 1980. The Acts of the Apostles. London: Inter-Varsity Press.

METZGER, BM 1971. A textual commentary on the Greek New Testament. London: UBS.

MOULTON, WF \& GEDEN, AS 1978. A concordance to the Greek Testament. Edinburgh: Clark.

SCHWEIZER, E 1984. The Good News according to Luke. Atlanta: John Knox.

TANNEHILL, RC 1985. Israel in Luke-Acts: A tragic story. JBL 104/1 (1985), 69-85.

VAN DER WATT, G 1982. Die vroeë Jerusalem-gemeente en die volk Israel. $M$ Thverhandeling, Universiteit van Stellenbosch.

WALASKY, PW 1983. And so we came to Rome. London: Cambridge University.

WILLIAMS, CSC 1964. The Acts of the Apostles. London: Black. 